\title{
Laços intergeracionais no contexto contemporâneo
}

\author{
Carolina de Campos Borges \\ Andrea Seixas Magalhães \\ Pontifícia Universidade Católica do Rio de Janeiro
}

\begin{abstract}
Resumo
O presente estudo aborda a articulação entre diferentes gerações na contemporaneidade. No contexto de transformações sociais aceleradas, discute-se a constituição dos laços intergeracionais, analisando mudanças subjetivas e relacionais. Ressalta-se que as diferenças geracionais estão na base do processo de transmissão sociocultural. A partir de estudos psicossociais, abordam-se distintas perspectivas teóricas do conceito de geração em contraposição à categoria idade. Destaca-se o caráter subjetivo da experiência de pessoas de diferentes idades e reflete-se sobre distanciamentos e aproximações entre esses sujeitos. Considera-se que, na contemporaneidade, os laços intergeracionais se estruturam de modo distinto e analisam-se as repercussões da homogeneização de valores baseada na juventude como ideal no processo de identificação intergeracional.
\end{abstract}

Palavras-chave: transformações sociais; relações intergeracionais; contemporaneidade

\begin{abstract}
Intergenerational bonds in the contemporary context. The present work concerns the articulation among different generations in the contemporary context. It discusses the constitution of intergenerational bonds, analyzing subjective and relational changes, in a context of accelerated social transformations. Generational differences are highlighted, since they are the basis of the socio-cultural transmission process. Different theoretical approaches of the generation concept are confronted with the category of age, from the perspective of psycho-social studies. It emphasizes experience subjective character and it discusses distances and proximities of people with different ages. It considers that contemporary intergenerational bonds are currently structured in a different way. The intergenerational identification process, based on the ideal of youth, stemming from the homogenization of social values, is analyzed.
\end{abstract}

Keywords: social changes; intergenerational relations; contemporary context

$\mathrm{E}$ ste trabalho discute o modo como se articulam as diferentes gerações no contexto da contemporaneidade. Questiona-se como o intenso e acelerado fluxo de transformações tecnológicas, econômicas, sociais e culturais, que caracteriza o mundo de hoje, repercute nas relações estabelecidas entre as pessoas de diferentes gerações.

A partir das contribuições de estudos psicossociais, buscase aqui refletir sobre as relações intergeracionais. Ressalta-se que não há sociedade que prescinda da transmissão cultural, que se faz de geração a geração, e na qual não haja diferenças intergeracionais. E, considerando-se que estes elementos, transmissão e diferenças entre gerações, estão na base dos laços intergeracionais, pergunta-se: de que modo a intensidade das transformações sociais contemporâneas afetam as relações intergeracionais?

No cenário atual, a forma acelerada e incessante com que as sociedades vêm se transformando em função da intensificação dos meios de comunicação, da globalização e da diversidade de influências culturais trazidas para as comunidades, tem significativas implicações para as relações intergeracionais. Assim, partindo do pressuposto de que a investigação das relações intergeracionais torna possível apreender o caráter dinâmico e complexo das relações sociais, a relação entre mudanças dos tempos e mudanças subjetivas e relacionais, este trabalho se propõe a explorar esta problemática.

O primeiro ponto a ser discutido é o uso do conceito de geração, em contraposição à categoria idade, destacando o caráter subjetivo da constituição da experiência de pessoas de diferentes idades. Em seguida, discute-se a relação intergeracional na contemporaneidade propriamente dita, questionando se hoje estaria ocorrendo um maior distanciamento entre as pessoas de diferentes gerações em função da discrepância de suas experiências pessoais produzida pela aceleração das transformações socioculturais. Ou, se, ao contrário, a dinâmica social contemporânea propicia uma maior proximidade entre as pessoas de diferentes gerações, na medida em que suas diferenças ficam diluídas em meio ao grande volume de inovações socioculturais produzidas continuamente. $\mathrm{Ou}$, ainda, se, diante disso tudo, estaria ocorrendo um re-posicionamento das pessoas de diferentes gerações na estrutura hierárquica social e familiar tradicional, estando os mais jovens servindo de modelo para os mais velhos, o fluxo de socialização se invertido. Deste modo, 
procura-se contribuir para o maior entendimento dos processos de constituição dos laços intergeracionais contemporâneos.

\section{O que é uma geração?}

De um modo geral, o conceito de geração destaca o papel da experiência na formação da subjetividade. Impõe-se, contudo, que sejam feitas algumas considerações sobre a complexidade dos fatores de estratificação social e sobre a convergência sincrônica de todos eles.

Ao falar geração, Debert (1998) afirma que "não se refere a pessoas que compartilham a mesma idade, mas às que vivenciaram determinados eventos que definem trajetórias passadas e futuras" (p. 60). Tal formulação é baseada na concepção de geração apresentada por Mannheim (1982), segundo a qual geração corresponde a um fenômeno cuja natureza é essencialmente cultural.

A geração reúne pessoas que, nascidas numa mesma época, viveram os mesmos acontecimentos históricos e partilham de uma mesma experiência histórica. Essa experiência comum dá origem a uma consciência que permanece presente ao longo do curso de suas vidas, influenciando a forma como os indivíduos percebem e experimentam novos acontecimentos.

Na perspectiva de Mannheim (1982), uma geração não se trata de um grupo concreto ou de uma comunidade, onde os laços que unem os indivíduos são conscientes e até desejados. Uma geração não pode se desfazer. Os membros de uma geração estão, sem dúvida, unidos entre si, mas em razão de um fenômeno social. A ligação que têm resulta da semelhante posição que ocupam dentro de um todo social.

Desta forma, pertencer a uma geração é como pertencer a uma classe social. Da mesma forma que aqueles que ocupam um mesmo segmento na sociedade compartilham de valores, afinidades, visões de mundo, etc., as pessoas que fazem parte uma mesma geração também estão ligadas umas às outras - mesmo que não o saibam, não o queiram e mesmo sem se conhecer -, mas essa ligação não é dada pela estrutura econômica.

O que Mannheim (1982) enfatiza é que as pessoas que nascem num mesmo ano ocupam uma posição comum na dimensão histórica do processo social - dependendo também, obviamente, da classe social, do gênero e da raça a que pertencem -, o que produz certa afinidade entre os indivíduos no que diz respeito a suas visões de mundo, suas experiências e suas formas de participação social. Isso, porque as experiências vividas por eles recaem sobre uma consciência semelhantemente "estratificada". É a estratificação da experiência, e não a simples coincidência cronológica, que vai propiciar a que as pessoas pertencentes a uma geração experimentem semelhantemente os acontecimentos. Por isso, o fato de pertencerem a uma determinada geração torna os indivíduos predispostos a pensar e a experimentar o mundo de um modo característico.

De acordo com Sarmento (2005), uma crítica que é comumente feita quanto ao uso do conceito de geração é que ele diluiria os outros importantes fatores de estratificação e ocultaria, numa designação comum, as diferenças e as igualdades de classe. Ciente desse risco e para prevenir isso, toma-se o conceito de geração não como diluindo os efeitos de classe, de gênero ou de raça na caracterização das posições sociais, e sim conjugando- se a eles. Assim, a uma geração integra-se o efeito de classe, de gênero e de raça, numa relação que não é aditiva e nem complementar, mas que afirma sua especificidade/singularidade. Por isso, então, por exemplo, jovens que hoje têm vinte anos podem experimentar de forma diferente acontecimentos atuais, dependendo da classe social a que pertença, do fato de se tratar de um homem ou de uma mulher, de um branco, um negro, um indígena, etc.; ou seja, a experiência geracional depende também de particularidades encontradas em cada universo cultural mais específico que atravessa as gerações.

Uma geração possui uma forte e visível identidade histórica, como afirma Barros (1987), e nela encontram-se implícitas as singularidades dos costumes e comportamentos que caracterizam a experiência de cada pessoa. Por se fazer o reconhecimento das identidades geracionais, pode-se compreender, por exemplo, a forma distinta com que antigamente e hoje mulheres ou homens investem no projeto de constituir uma família ou de construir uma carreira profissional; como são diferentes as formas de perceber, sentir e agir de mulheres e homens que vivem em cidades grandes em relação àqueles que vivem em cidades pequenas; a maior facilidade com que os jovens encaram a tecnologia em comparação com os mais velhos; ou, fazendo referência ao exemplo dado por Mannheim (1982), as diferenças entre jovens da China e da Alemanha em 1800.

Deve-se esclarecer que, ao se falar em geração, parte-se da crença de que a realidade é socialmente construída. Conforme Berger e Luckmann (1974), o homem, diferentemente dos outros animais, tem uma relação com o mundo/ambiente estruturada de forma imperfeita devido a sua própria constituição biológica. $\mathrm{O}$ processo de tornar-se indivíduo efetua-se na correlação com o ambiente, mais precisamente com uma ordem cultural e social específica. Desde o momento do seu nascimento, até o seu desenvolvimento orgânico, uma pessoa está submetida a uma contínua interferência socialmente determinada.

Assim, considera-se: primeiro, que o indivíduo produz a si mesmo, de modo que o eu não pode ser devidamente compreendido fora do particular contexto social em que foi formado; segundo, que a sua auto-produção é necessariamente um empreendimento social (Berger \& Luckmann, 1974).

Berger e Luckmann (1974) consideram também que a realidade é socialmente construída. A relação entre o homem, o produtor, e o mundo social - produto dele -, é sempre uma relação dialética, ou seja, o indivíduo e seu mundo social atuam reciprocamente um sobre o outro. Toda atividade humana está sujeita ao hábito e, quando isso ocorre, um significado se inclui a ela. Por meio do processo de interiorização, o mundo de coisas e significados é concebido como uma realidade exterior. Assim, institui-se um mundo experimentado como realidade objetiva.

Para efeito do estudo sobre gerações, tudo isso é importante, pois o processo de transmissão cultural que se faz de uma geração a outra (por exemplo, no processo de socialização) é justamente a transmissão de uma realidade, de um mundo de hábitos e de significados. E essa transmissão se dá a partir de relações com "outros significativos" que pertencem a diferentes gerações.

Conforme Berger e Luckmann (1974), a determinação do que seja uma realidade e um conhecimento depende dos contextos sociais específicos a que se referem. A "sociologia do 
conhecimento" tratará justamente do conhecimento estabelecido como realidade, da relação entre o pensamento humano e o contexto social dentro do qual este surge, e analisará como se dá a construção social da realidade.

Karl Mannheim foi um sociólogo que, de acordo com Berger e Luckmann (1974), muito acrescentou à "sociologia do conhecimento". Na sua compreensão, a sociedade determinava o conteúdo da ideação humana e não haveria pensamento humano que fosse imune às influências do contexto social. Portanto, um conhecimento haveria de ser sempre conhecimento a partir de uma determinada posição.

Essas considerações são fundamentais para se entender exatamente o sentido do termo geração nos estudos relacionados à temática geracional. A perspectiva das gerações pode ser muito interessante para a análise das relações estabelecidas, por exemplo, na família, em que estão reunidas pessoas que vêm de tempos diferentes, que nasceram e cresceram em momentos distintos e, por isso, pessoas que percebem e sentem os acontecimentos do presente de maneiras diferentes. É nesse sentido que se questiona, neste trabalho, como as relações intergeracionais estariam ocorrendo hoje.

Uma das aplicações das reflexões sobre o conceito de geração acima tecidas é que hoje, devido à aceleração das mudanças socioculturais, as pessoas de diferentes gerações podem estar referenciadas a realidades muito diferentes. Assim, numa família, por exemplo, avós "tradicionais", seus filhos "liberais" e os netos "tecnológicos" comporiam uma imagem que retrata um pouco essa realidade, embora este seja um retrato estereotipado. $\mathrm{O}$ que se observa e será discutido logo a seguir, é que essas três gerações sofrem as influências contemporâneas simultaneamente, embora cada uma delas as experimente de forma diferente, de modo singular, já que isso também depende de processos subjetivos individuais.

\section{Gerações e mudança social}

A análise do impacto de transformações socioculturais em pessoas de diferentes gerações não é, de forma alguma, um assunto inédito. Trata-se de uma temática já explorada por diversos autores, levando em consideração outros momentos históricos em que também impressionava a velocidade das transformações sociais.

O período de industrialização e urbanização da sociedade, na modernidade, por exemplo, já foi bastante explorado. Alguns estudos buscaram avaliar o impacto das mudanças sociais nas histórias de famílias de origem rural que se deslocavam para as cidades e as consequências do fato de pessoas de diferentes idades, pertencentes a uma mesma família, deixarem suas casas para viverem em um mundo novo. Segundo pesquisa realizada na França (Segalen, 1995), a saída de uma família do meio rural para se inserir no meio urbano instaura uma ruptura com as formas de vida das gerações passadas, tornando maiores e mais visíveis as diferenças intergeracionais, o que abalou as bases da hierarquia social que se estruturava na ideia de sabedoria da pessoa mais experiente.

Portanto, guardadas as devidas proporções, certamente podemos encontrar na história situações semelhantes ou análogas às que vivemos hoje. Desta forma, pode ser bastante oportuna a retomada de algumas reflexões realizadas em outros contextos históricos para entendermos a relação entre as gerações e os processos de mudança no mundo de hoje.

A problemática da integração das gerações em contextos de intensas e aceleradas transformações socioculturais foi um assunto explorado por Mannheim (1982) e resultou na elaboração do que o autor conceituou como problema das gerações. $\mathrm{O}$ problema das gerações dá uma boa medida dos impactos da aceleração das transformações sociais e culturais nas relações intergeracionais.

Conforme o autor, na base do problema das gerações está a concepção de tempo. Fazendo um breve apanhado sobre as formas possíveis de se tratar o problema das gerações - a abordagem positivista e a romântica histórica - Mannheim (1982) afirma que dentro da tradição positivista, francesa, esse problema é tratado tomando-se o tempo quantitativamente. Partese da hipótese de que as gerações mudam em corrente contínua, ou seja, quando alguém morre, outra nasce para substituí-la, havendo um intervalo constante entre as gerações. Nessa forma de apreender a noção de tempo, numa lógica quase aritmética, no entanto, o objetivo seria encontrar uma lei geral para exprimir o ritmo do desenvolvimento histórico, baseado na lei biológica da duração limitada de vida do homem e na concepção de sobreposição das gerações novas e velhas. De acordo com esse modo reducionista de ver o problema das gerações, privilegiamse questões quantitativas e, por isso, a história das ideias, ou seja, da transformação das ideias, ficaria limitada ao nível cronológico (Mannheim, 1982).

Segundo Mannheim (1982), na perspectiva desenvolvida na Alemanha, a formulação romântica histórica desta questão dá ao problema das gerações novos contornos. Nessa perspectiva, ele é definido a partir de outra concepção de tempo, a do tempo qualitativo, o tempo da experiência. Assim, passa a ser considerada a existência de um tempo interior que não pode ser medido, mas apenas experimentado em termos puramente qualitativos. O tempo que separa as gerações não é mais tomado como o tempo quantitativo, cronológico, mas sim como o tempo qualitativo, o tempo que é vivido e que constitui cada indivíduo.

Com isso, entende-se que, mesmo que diferentes gerações vivam num mesmo tempo, todas elas na verdade vivem em eras subjetiva e qualitativamente diferentes. Assim, considera-se que existe "não contemporaneidade" no contemporâneo. Ou seja, numa sociedade, convivem pessoas com uma mesma idade e com idades diferentes. Para cada uma delas o "presente" que vivem é um momento diferente, já que o agora representa um diferente período do seu eu, que só poderia ser partilhado com as pessoas da mesma idade. Assim, cada momento do tempo é mais do que um acontecimento pontual, pois é experimentado diferentemente por pessoas de várias gerações que estão vivenciando diferentes etapas de desenvolvimento. Nessa perspectiva, cada geração constrói uma "enteléquia" própria, o que pode ser compreendido por analogia ao conceito de "espírito de uma época" ou Zeitgeist.

Para o mesmo autor, nessa construção teórica o fator social não é aludido na enumeração dos fatores determinantes para a formação de uma enteléquia. Por isso, Mannheim (1982) considera romântica tal abordagem do problema das gerações. Embora não negue a existência das "enteléquias", 
o autor considera que abstrair delas o fator social é torná-la menos realista, como se fosse referida mais a uma dimensão puramente espiritual e não pudesse ser compreendida em termos de processos culturais.

$\mathrm{Na}$ tentativa de superar essas duas abordagens do problema das gerações, mas não deixando de considerar as importantes contribuições de cada uma delas para a análise desta questão, Mannheim (1982) apresenta seu esboço do que chama "o problema sociológico das gerações", destacando sua importância para apreendermos a velocidade acelerada das mudanças sociais do nosso tempo.

Segundo ele, a vida social se constitui dentro de um processo que não se interrompe nunca: a) novos participantes aparecem no processo cultural (as pessoas nascem) enquanto que b) outros desaparecem (as pessoas morrem); c) os membros de qualquer geração só podem participar numa secção temporariamente limitada do processo histórico (o tempo de vida); d) tornase necessário transmitir continuamente a herança cultural acumulada (transmissão cultural intergeracional); e) a transição de uma geração a outra é um processo contínuo. É impossível imaginarmos uma sociedade que não se processe desta forma: em que uma geração não dê lugar a outras; em que não haja transmissão cultural que possibilite a preservação de uma memória social; em que parte do conteúdo cultural transmitido pelas gerações mais velhas não seja esquecido, em que não haja inovação cultural (Mannheim, 1982).

Mas a localização de uma geração dentro desse processo, contudo, não é mecânica. Mannheim (1982) chama a atenção para o fenômeno da "estratificação" da experiência. Estar em uma posição semelhante é o fato de se encontrarem em posição de experimentarem os mesmos acontecimentos e os mesmos dados e isso não se dá somente com a contemporaneidade cronológica.

É claro que o critério cronológico é importante para o agrupamento geracional, já que situa os indivíduos em períodos históricos. No entanto, o critério de idade não é suficiente para distinguir grupos de pessoas no que se refere a suas experiências de vida, à construção de suas visões de mundo ou aos diferentes modos de inserção no corpo social. Tudo isso vai depender também do seu posicionamento social de forma mais ampla, incluindo desde a sua localização geográfica até distinções como raça, gênero e classe social.

Nesta discussão, convém também destacar que, mesmo dentro de uma mesma geração, pode-se formar o que Mannheim (1982) denomina "unidade geracional", definida como um laço mais concreto entre os membros de uma geração determinado pelo fato de um grupo dentro da mesma geração real trabalhar diferentemente o material da sua experiência comum. Isso implica em que, dentro de qualquer geração, existam várias unidades de geração diferenciadas, antagônicas. Algumas delas podem assumir efeitos socializantes, dependendo da importância socialmente atribuída aos dados mentais compartilhados pelos seus membros. Um exemplo de "unidades geracionais" pode ser visto na geração de jovens na década de 1960, no Brasil, onde dois grupos contrastantes, um mais conservador e outro mais liberal faziam parte da mesma geração. O segundo grupo afirmou-se como unidade socializadora para as gerações futuras em decorrência da influência que as idéias liberais tiveram para as mudanças dos padrões sociais instituídos posteriormente, embora, como diversos estudos apontam, mudanças sociais sejam marcadas também por permanências de padrões e ambivalências.

A formulação do "problema das gerações" apresentada por Mannheim (1982) é bastante oportuna para iniciar uma discussão sobre as relações que se estabelecem entre as pessoas de diferentes gerações atualmente. Observa-se que a intensidade e a aceleração dos processos de mudanças tecnológicas, sociais, culturais e econômicas, que caracterizam o mundo de hoje, afetam as relações e os tipos de laços sociais que unem as pessoas de diferentes gerações dentro da família e também fora dela. Isso, porque, assim como uma geração reúne alguns indivíduos, ela também produz distinções entre eles em relação àqueles que são de outras gerações, distinções essas que são mais marcantes quando se trata de um contexto de aceleradas mudanças socioculturais. Ressalta-se que quanto maior o fluxo das mudanças sociais, maior é a discrepância entre as experiências de cada geração. Consequentemente, maior é a acentuação das diferenças intergeracionais.

A partir disso, pode-se novamente refletir sobre as bases que estruturam as relações intergeracionais contemporaneamente. As pessoas de diferentes gerações, hoje, tendem realmente a se conceberem diferentes umas das outras? Em que medida isso se dá? E, a partir disso, que tipo de vínculos podem elas estabelecer umas com as outras?

\section{Articulação intergeracional na contemporaneidade}

Seguindo o pensamento Mannheimiano, as diferenças intergeracionais são inerentes à estrutura social, uma vez que os indivíduos, posicionados nas suas respectivas gerações, estariam mais ou menos predestinados a verem o mundo de uma forma própria e distinta daqueles que pertencem a outras gerações. Assim, existiria uma distância insuperável entre as pessoas de diferentes gerações, a qual legitimaria as diferenças intergeracionais.

Contudo, considerando estudos desenvolvidos por Pais (1998), pode-se chegar a outras conclusões a esse respeito. Segundo o autor, em contextos de transformação, as relações intergeracionais apresentam fluxos recíprocos de socialização que podem ser mais ou menos tensos à medida que diferentes gerações tenham perspectivas, expectativas ou representações mais ou menos distintas sobre a sociedade.

O autor, com base em subdivisão das culturas anteriormente feita por Mead (1971), subdivide as culturas nas seguintes categorias: post-figurativa, isto é, em que há prevalência das tradições e costumes e de um sentimento de continuidade etária; cultura configurativa, marcada pela descontinuidade intergeracional; e pré-figurativa, em que os jovens tornam-se os agentes socializadores das gerações mais velhas.

Pais (1998) afirma que, na sociedade contemporânea, o modelo que prevalece corresponde ao da cultura pré-figurativa e que, nela, as descontinuidades intergeracionais só não se acentuam caso as gerações mais velhas se mostrem relativamente permeáveis e não ofereçam resistências às mudanças lideradas pelos mais jovens.

A centralidade da juventude na cultura contemporânea é 
assinalada também por outros diversos autores. Vianna (2003) assinala o objetivo permanente das pessoas de todas as idades de ser jovem e de se manter jovem e, diante disso, que a juventude atualmente se transformou em uma mercadoria vendida às pessoas de todas as gerações. Kehl (2004) também observa que ser jovem hoje é muitas vezes relacionado a um estado de espírito que está necessariamente vinculado à criação de uma imagem de si mesmo projetada por meio de adereços e vestimentas jovens, acessíveis a pessoas de todas as idades.

$\mathrm{O}$ incentivo ao consumo de atributos jovens conduz à constatação de que ser jovem no mundo hoje é desfrutar de um prestígio, construído a partir de um discurso que afirma que ser jovem é bom para todos. Para Kehl (2004), o prestígio de ser jovem pode estar relacionado com uma estratégia de marketing lançada para seduzir uma faixa de consumidores que vivia esquecida por comportar pessoas dependentes financeiramente dos pais e sem poder de decisão no espaço público. A partir do momento em que ser jovem transformou-se em um slogan, a juventude tornou-se uma categoria social e economicamente importante. Assim, ela constituiu-se como um valor e passou a atrair milhares de pessoas para o mercado de consumo em busca dos seus atributos.

Ao vincular juventude e consumo, a cultura adolescente, traduzida por símbolos como a liberdade, a beleza e a sensualidade, é lançada num campo de identificações que abarca todas as idades e produz desejos de eterna juventude para todas as gerações. A teenagização da cultura torna-se, deste modo, segundo a autora, uma marca problemática dos nossos dias. Quando adultos se espelham nos ideais teen, deixam de se orientar pelos ideais dos adultos, deixam de valorizar sua experiência, deixam vazio o lugar de adulto. Isso gera um esvaziamento do sentido da vida que é caracterizado pela autora como algo "difícil de suportar". Porque, quando buscam se espelhar nos adultos, os jovens encontram uma imagem deformada de si mesmo.

Com base nesse enfoque, Kehl (2004) toma a juventude como um sintoma da cultura. Ao falar isso, a autora está enfatizando que o enaltecimento da juventude é uma construção cultural, e não natural, que legitima uma forma de integração social regida pelo imperativo do gozo. É dentro desse contexto que Vianna (2003) aponta a mistura das diferentes gerações nos espaços sociais e a dificuldade de se identificar os que não são jovens em meio aos grupos de pessoas, pois todos parecem jovens.

Claro que corrobora também para a ênfase que a cultura contemporânea coloca na figura do jovem o fato de ser esta a primeira geração a crescer sob as condições do mundo globalizado, isto é, conectados ao mundo, tendo à disposição enormes volumes de informação de todas as partes do planeta e experimentando, desde pequenos, o mundo veloz e multifacetado da tecnologia. Sendo eles os "sujeitos contemporâneos por excelência", conforme denominação atribuída por Coutinho (2002), eles se sentem nitidamente mais à vontade com as transformações que assustam e angustiam as gerações dos mais velhos, o que ressalta as diferenças que os distinguem.

Por tudo isso, hoje, considera-se que as novas gerações sejam não só portadoras de valores diferentes dos partilhados pelas gerações mais velhas, mas, mais do que isso, que elas vêm se constituindo num importante quadro de referência para as gerações mais velhas, possibilitando certa horizontalidade intergeracional de valores.

Tudo isso traduz muito bem o que Pais (1998) quer transmitir quando afirma que hoje é como se os processos de socialização tivessem sofrido uma inversão de sentido. O que há de novo na atualidade, segundo ele, é a capacidade que os jovens têm de influenciar o mundo dos adultos e a permeabilidade das gerações mais velhas a essas influências.

Segundo esse raciocínio, concluiríamos, então, que existe uma tendência a que muitos jovens e muitas pessoas das gerações mais velhas cheguem aos mesmos valores, o que se explicitaria pelo caráter pacífico das relações intergeracionais. Assim, o autor explica o fato de as famílias tradicionais, hiperestruturadas, estarem dando lugar a famílias estruturalmente mais flexíveis. Estar-se-ía, então, passando de um modelo hierárquicoautoritário a um modelo igualitário-democrático de família, em que os jovens, com relação a alguns domínios, "sabem mais" do que seus pais e as relações entre pais e filhos se encontram mais desreguladas ou carentes de referenciais mais estáveis e nítidos.

A horizontalidade das relações intergeracionais, de acordo com Magalhães e Féres-Carneiro (2004), pode ser problemática no que se refere à construção do vínculo entre pessoas de diferentes gerações, enfraquecendo os laços de solidariedade e de reciprocidade. Segundo as autoras, pelo fato de as instituições sociais serem menos estáveis, mais frágeis e temporárias, os elos sociais podem se tornar enfraquecidos e insuficientes para a manutenção de compromissos e de acordos mútuos.

Dentro desta reflexão sobre os laços intergeracionais contemporâneos, poderia se considerar a posição de Pais (1998) diferente da de Mannheim (1982) quanto à dinâmica das relações intergeracionais em contextos de intensas mudanças sociais. O primeiro ressalta o processo de homogeneização de valores intergeracionais e o segundo enfatiza as diferenças insuperáveis, pois estruturais do ponto de vista social, entre as diferentes gerações.

No entanto, embora Pais (1998) defenda a existência hoje de uma disposição para a igualdade de valores entre as diferentes gerações, o autor assinala as sutilezas envolvidas nesse processo de homogeneização dos valores, conciliando-se com o posicionamento de Mannheim (1982) e complexificando este debate.

Pais (1998) assinala que o modo de apreender um mesmo valor pode ser diferente nas distintas gerações. Por exemplo: valores como o individualismo ou a solidariedade são apreendidos por jovens e velhos de formas um tanto distintas. Com relação aos jovens, o individualismo leva ao expressionismo. Para os mais velhos, ao materialismo. A solidariedade, para os jovens, é mais convivial, enquanto que para os mais velhos é mais moral.

Isso indica, portanto, que o fato de diferentes gerações estarem vivendo na contemporaneidade não elimina as especificidades das visões de cada uma delas. As mudanças históricas e culturais numa sociedade são experimentadas, ao mesmo tempo, por pessoas de diferentes gerações, como, por exemplo, avós, seus filhos e seus netos. Contudo, por serem diferentes seus posicionamentos geracionais, cada um deles 
interpretará e se influenciará por essas mudanças de forma distinta - ressalvando-se que, mesmo dentro de uma mesma geração, pode haver diferenças entre grupos, como aponta a categoria mannheimiana "unidades de geração".

Apesar disso, forças culturais impelem as pessoas de gerações diferentes a basearem seus ideais em modelos semelhantes, muitas vezes calcados nos atributos da juventude, na ideia de um "ser contemporâneo por excelência", o que seria, de certa maneira, a negação daquilo que não é atual, do que pertence às "outras" gerações.

Assim, podemos concluir que o vínculo intergeracional contemporâneo, de uma forma geral, configura-se por meio de uma tensão decorrente da conciliação da ideia de diferença e homogeneização intergeracional. Diferença estruturalmente dada. Homogeneização culturalmente produzida no contexto contemporâneo.

\section{Considerações finais}

No que se refere à constituição dos vínculos intergeracionais, o contexto contemporâneo apresenta como particularidade a conjugação de elementos opostos, pressionando para a diferenciação e para a homogeneização intergeracional, simultaneamente. A aceleração das mudanças sócio-culturais, tecnológicas, econômicas, etc, traduz-se nas relações intergeracionais acentuando as distinções entre as gerações, mas também favorecendo uma inversão nos processos de socialização e de transmissão de saberes e valores de geração a geração.

Apreendendo, por um lado, a diferença intergeracional socialmente estruturada e, por outro lado, a tendência atual à homogeneização de valores que perpassa as diferentes gerações, pode-se finalmente compreender quão tensamente se constitui o vínculo intergeracional na contemporaneidade. Equilibrando vetores de distinção e de igualdade, as relações estabelecidas pelas pessoas de diferentes gerações, hoje, incorporam e expressam os paradoxos sociais contemporâneos.

Todavia, pode-se argumentar que, em outros contextos sociais, em que as transformações não se davam de forma tão aceleradas e acentuadas como hoje, os elos intergeracionais também eram constituídos tendo como base a ideia de diferença e de igualdade. Mas, analisando mais de perto essa questão, podese compreender que, em cada contexto, diferença e igualdade adquirem sentidos particulares.

Outrora, a diferença entre as gerações se afirmava claramente, sendo nítida a delimitação das fronteiras entre as idades, assim como visíveis e declaradas as diferentes posições ocupadas por cada um. Os comportamentos próprios de cada faixa etária, bem como as vestimentas e as imagens corporais produzidas, tudo isso demarcava os limites entre os grupos de diferentes idades e sinalizava as diferentes posições ocupadas pelos indivíduos de cada geração.

Apesar das distinções expressas, a ideia de igualdade está presente e pode ser detectada por meio daquilo que propicia a transmissão cultural das gerações mais velhas para as gerações mais jovens. Essa transmissão, de certo modo, era possível justamente porque os mais jovens se identificavam com os mais velhos. Pelo processo de identificação entre as gerações, os mais jovens podiam arquitetar uma imagem de si mesmos no futuro, imagem esta calcada na figura dos mais velhos. É a isto que se refere a ideia de igualdade fundadora dos laços intergeracionais, anteriormente mencionada.

É, portanto, neste sentido que se afirma que, nos contextos sociais anteriores à contemporaneidade, o vínculo intergeracional também se constituía pela conjugação de dois opostos, diferença e igualdade: graças ao fato de se poder encontrar semelhança entre as pessoas de diferentes gerações, de haver uma concepção de "eu" no futuro que encontra correspondência naquele "outro".

No contexto contemporâneo, os laços intergeracionais se constituem de modo muito diferente. Hoje, a diferença intergeracional é acentuada, mas não é expressa de forma tão nítida, encontrando-se camuflada pela homogeneização de valores baseada na juventude como ideal. Assim, a ideia de igualdade na constituição dos vínculos intergeracionais se faz de forma inversa: pela possibilidade de identificação dos mais velhos com os mais jovens. É justamente quando o mais velho se mostra investido de atributos da juventude que ocorre a identificação intergeracional, processo que se efetua, muitas vezes, pela negação das diferenças que definem cada geração. Deste modo, ocorrendo o espelhamento dos mais velhos nos mais jovens, fica o "eu" que se projeta para o futuro sem alvos de correspondência.

\section{Referências}

Barros, M. L. (1987). Autoridade e afeto: filhos e netos na familia brasileira. Rio de Janeiro: Jorge Zahar.

Berger, P. L., \& Luckmann, T. (1974). A construção social da realidade: tratado de sociologia do conhecimento. Petrópolis: Vozes.

Coutinho, L. G. (2002). Ilusão e errância: adolescência e laço social contemporâneo na interface entre a psicanálise e as ciências sociais (Tese de doutorado não publicada). Pontifícia Universidade Católica do Rio de Janeiro, Rio de Janeiro).

Debert, G. G. (1998). A antropologia e o estudo dos grupos e das categorias de idade. In M. L. de Barros (Org.), Velhice ou terceira idade? (pp. 49-68). Rio de Janeiro: Fundação Getúlio Vargas.

Kehl, M. R. (2004). A juventude como sintoma da cultura. In R. Novaes \& P. Vannuchi (Orgs.), Juventude e sociedade: trabalho, educação, cultura e participação (pp. 89-113). São Paulo: Fundação Perseu Abramo.

Magalhães, A. S., \& Féres-Carneiro, T. (2004). Transmissão psíquica geracional na contemporaneidade. Psicologia em Revista, 10, 243-255.

Mannheim, K. (1982). A questão das gerações. In M. M. Foracchi (Org.), Sociologia (pp. 67-95). São Paulo: Ática.

Mead, M. (1971). Le Fossé des générations. Paris: Denoël/Gonthier.

Pais, J. M. (1998). Introdução. In J. M. Pais (Org.), Gerações e valores na sociedade portuguesa contemporânea (pp. 17-58). Lisboa: Instituto de Ciências Sociais - Secretaria de Estado da Juventude.

Sarmento, M. J. (2005). Gerações e alteridade: interrogações a partir da sociologia da infância. Revista Educação e Sociedade, 26(91), 361-378.

Segalen, M. (1995). Continuités et discontinuités familiales: approche sóciohistorique du lien intergénérationnel. In C. Attias-Donfut (Org.), Les solidarités entre générations: vieillesse, familles, état (pp. 27-40). Paris: Nathan.

Vianna, H. (2003). Introdução. In H. Vianna (Org.), Galeras cariocas: territórios de conflitos e encontros culturais (pp. 7-16). Rio de Janeiro: EDUFRJ. 
Carolina de Campos Borges é doutora em Psicologia Clínica pela Pontifícia Universidade Católica do Rio de Janeiro. Endereço para correspondência: Rua G, Quadra 811, Lotes 13/14 Vila Santa Tereza - Goiânia/ GO. CEP: 74633-280. Telefone: (62)3261-1347. E-mail: carolinacambor@gmail.com Andrea Seixas Magalhães, doutora em Psicologia Clínica pela Pontifícia Universidade Católica do Rio de Janeiro, é professora Assistente do Departamento de Psicologia da mesma universidade. E-mail: andreasm@ puc-rio.br 